\title{
Embolization of the Middle Meningeal Artery Effectively Treats Refractory Chronic Subdural Hematoma: A Systematic Review
}

\author{
Alfotih Gobran*, Fang-Cheng Li, Xin-Ke Xu, Shang-Yi Zhang \\ Sun Yat Sen Memorial Hospital, Neurosurgery Department, Sun Yat Sen Medical University, \\ P.O. Box 510120, GuangZhou, GuangDong Province, People’s Republic of China
}

\begin{abstract}
Chronic subdural hematoma (CSDH) formation mechanism is very complex, and has not entirely understood. It represents a frequent type of intracranial hemorrhage, and is very common disease in Neurosurgery practice, especially in older patients. Various surgical treatments have been proposed for the treatment of $\mathrm{CSDH}$. The rate of recurrence in $\mathrm{CSDH}$ after surgery ranges from $5 \%$ to $30 \%$, repeated surgery must be considered. But in some cases subdural collections are still persistent. Endovascular embolization of the middle meningeal artery (MMA) is an option for treatment of refractory $\mathrm{CSDH}$. We review all cases that were treated with embolization to assess the effect of this intervention. Our review revealed 6 papers with a total enrollment of 14 patients were treated with MMA embolization for refractory chronic subdural hematoma without any postoperative complication or recurrence. In this study we suggest MMA embolization as an alternative for treatment of non-curable CSDH, especially for old people with systematic diseases, who cannot tolerate repeat surgery.
\end{abstract}

\section{Introduction}

Chronic subdural hematoma (CSDH) is a common neurological condition, particularly for older patients $(1,2)$, with an estimated incidence of 7.32 per 100,000 people per year for individuals above 70 years old (3). Levels of mortality associated with $\mathrm{CSDH}$ range from $1.5 \%$ to $8 \%$ (4). The pathogenesis of $\mathrm{CSDH}$ formation remains unclear, although new imaging and molecular biology techniques have improved our understanding of these processes $(5,6)$. The rate of recurrence in $\mathrm{CSDH}$ after surgery with any of actual techniques (Burr-hole surgery with irrigation and drainage, twist drill, craniotomy) ranges from $5 \%$ to $30 \%(7,8,9)$. Patients who have high risk factors for recurrence, especially with coagulopathy10 or under anticoagulant therapy (11), hematoma may be recur after the first intervention, and repeated surgery must be considered. The treatment options remains controversial. A number of techniques are used to manage recurring $\mathrm{CSDH}$, including burr hole plus drainage, repeated irrigation, the installation of reservoirs and aspiration 
(12), subdural peritoneal shunts (13), capsule removal with large craniotomy, and the endoscopic perforation of the septum (14).

For elderly patients, however, efforts should be made to avoid the repeated application of invasive procedures. Embolization of the middle meningeal artery (MMA) is another treatment option for frequently recurring CSDH. This procedure is often used to treat dural arteriovenous shunts or as a preoperative treatment for meningioma tumors. MMA embolization was first used to treat CSDH in 2000, preventing $\mathrm{CSDH}$ recurrence in a patient with cirrhosis of the liver (15).

Here we have evaluated whether MMA embolization effectively prevents the recurrence of hematoma in patients with CSDH.

A search of the literature revealed six reports concerning 14 patients. These patients were 55-87 years old and had follow-up periods of 3-18 months. None of the patients treated with MMA embolization for refractory $\mathrm{CSDH}$ experienced any postoperative complications or hematoma recurrence. This analysis suggests that MMA embolization is an effective, alternative treatment for noncurable CSDH, especially for older patients with systematic diseases who cannot tolerate multiple surgeries.

\section{Methods}

To identify relevant case reports in the scientific literature, the Medline, PubMed, Embase, and ISI Web of Science databases were searched using the key words "chronic subdural hematoma" combined with "recurrence" and "embolization" or "middle meningeal artery". Only patients who received MMA embolization for the treatment of recurrent $\mathrm{CSDH}$ were included in the analysis. Articles not available in English were excluded. After identifying relevant articles, all studies referenced by these manuscripts were also reviewed. Our search identified six publications that describe outcomes for 14 patients treated with MMA embolization. Included studies were case series that presented class III evidence.

\section{Results}

Among the 14 patients who met our inclusion criteria were 12 males and two females, with ages that ranged from 55 to 87 years (Table 1). Seven patients had suffered a previous head trauma; three patients had not experienced a trauma; trauma histories were not available for three patients; and for patient number 9 the history of head trauma was unclear. Patients presented with symptoms that included abnormal behavior, disorientation, speech abnormalities, dementia, motor weakness, hemiparesis, gait disturbances, and loss of consciousness.

Three patients were taking the anticoagulant Warfarin (Coumadin), one patient had coagulopathy from cirrhosis of the liver, one patient was on hemodialysis because of chronic renal failure, one patient was receiving chemotherapy for peritoneal mesothelioma, one patient was receiving treatment for dentatorubral-pallidoluysian atrophy, one patient was suffering from alcoholism, and six patients had no previous medical histories. Based on computed tomography scans, six patients had bilateral CSDH, whereas eight patients had onesided CSDH. 
TABLE 1

Patients' characteristics

\begin{tabular}{|c|c|c|c|c|c|c|c|c|c|c|c|}
\hline \multirow[t]{2}{*}{ author } & \multirow[t]{2}{*}{$\begin{array}{l}\text { Patient } \\
\text { No. }\end{array}$} & \multirow[t]{2}{*}{ Age } & \multirow[t]{2}{*}{$\operatorname{sex}$} & \multirow[t]{2}{*}{$\begin{array}{l}\text { Head } \\
\text { Trauma? }\end{array}$} & \multirow[t]{2}{*}{$\begin{array}{l}\text { Pre-treatment } \\
\text { Symptoms }\end{array}$} & \multirow[t]{2}{*}{$\begin{array}{l}\text { Past medical } \\
\text { history }\end{array}$} & \multirow[t]{2}{*}{$\begin{array}{l}\text { CSDH } \\
\text { on } C T\end{array}$} & \multicolumn{2}{|c|}{\begin{tabular}{|l} 
pre-embolization \\
treatments
\end{tabular}} & \multirow[t]{2}{*}{$\begin{array}{l}\text { Embolization } \\
\text { Materials }\end{array}$} & \multirow[t]{2}{*}{$\begin{array}{l}\text { Follow-up } \\
\text { (months) }\end{array}$} \\
\hline & & & & & & & & $\begin{array}{l}\text { major } \\
\text { treatments }\end{array}$ & $\begin{array}{l}\text { other } \\
\text { treatments }\end{array}$ & & \\
\hline $\begin{array}{l}\text { Mandai } \\
\text { et al. }^{15}\end{array}$ & 1 & 59 & $\mathrm{M}$ & no & $\begin{array}{l}\text { LOC, } \\
\text { hemiparesis }\end{array}$ & $\begin{array}{l}\text { coagulopathy } \\
\text { from cirrhosis } \\
\text { of the liver }\end{array}$ & $\begin{array}{l}\text { 1) } \\
\text { bilateral } \\
\text { 2) MLS }\end{array}$ & $\begin{array}{l}\text { burr hole, } \\
\text { irrigation }\end{array}$ & $\begin{array}{l}\text { Ommaya } \\
\text { reservoir }\end{array}$ & $\begin{array}{l}\text { PVA } \\
\text { particles }\end{array}$ & 7 \\
\hline \multirow[t]{2}{*}{$\begin{array}{l}\text { Hirai } \\
\text { et al. } .^{27}\end{array}$} & 2 & 81 & $\mathrm{M}$ & yes & $\begin{array}{l}\text { motor } \\
\text { weakness, gait } \\
\text { disturbance }\end{array}$ & $\begin{array}{l}\text { warfarin } \\
\text { (aortic valve } \\
\text { replacement) }\end{array}$ & bilateral & $\begin{array}{l}\text { burr hole, } \\
\text { irrigation }\end{array}$ & irrigation & $\begin{array}{l}\text { PVA } \\
\text { particles, } \\
\text { platinum } \\
\text { coils } \\
\end{array}$ & 10 \\
\hline & 3 & 63 & M & yes & $\begin{array}{l}\text { abnormal } \\
\text { behavior, } \\
\text { disorientation }\end{array}$ & $\begin{array}{l}\text { warfarin } \\
\text { (cardiomyop- } \\
\text { athy) }\end{array}$ & $\begin{array}{l}\text { right } \\
\text { side }\end{array}$ & $\begin{array}{l}\text { burr hole, } \\
\text { irrigation, } \\
\text { drainage }\end{array}$ & irrigation & $\begin{array}{l}\text { platinum } \\
\text { coils }\end{array}$ & unavailable \\
\hline $\begin{array}{l}\text { Ishihara } \\
\text { et al. }^{28}\end{array}$ & 4 & 78 & $\mathrm{M}$ & yes & unavailable & $\begin{array}{l}\text { hemodialysis } \\
\text { (chronic renal } \\
\text { failure) }\end{array}$ & left side & $\begin{array}{l}\text { burr hole, } \\
\text { drainage }\end{array}$ & none & $20 \%$ NBCA & 16 \\
\hline \multirow[t]{4}{*}{$\begin{array}{l}\text { Mino } \\
\text { et al. }{ }^{29}\end{array}$} & 5 & 73 & $\mathrm{M}$ & yes & $\begin{array}{l}\text { gait } \\
\text { disturbance }\end{array}$ & none & bilateral & $\begin{array}{l}\text { burr hole, } \\
\text { drainage }\end{array}$ & irrigation & $\begin{array}{l}\text { gelatin } \\
\text { sponge, GDC }\end{array}$ & 6 \\
\hline & 6 & 79 & $\mathrm{M}$ & no & $\begin{array}{l}\text { speech } \\
\text { disturbance, } \\
\text { dementia }\end{array}$ & none & $\begin{array}{l}\text { right } \\
\text { side }\end{array}$ & $\begin{array}{l}\text { burr hole, } \\
\text { drainage }\end{array}$ & Craniotomy & \begin{tabular}{|l} 
gelatin \\
sponge, GDC
\end{tabular} & 6 \\
\hline & 7 & 65 & M & yes & hemiparesis & none & left side & $\begin{array}{l}\text { burr hole, } \\
\text { drainage }\end{array}$ & none & $\begin{array}{l}\text { gelatin } \\
\text { sponge, GDC }\end{array}$ & 6 \\
\hline & 8 & 75 & $\mathrm{M}$ & yes & \begin{tabular}{|l} 
gait \\
disturbance \\
\end{tabular} & none & bilateral & $\begin{array}{l}\text { burr hole, } \\
\text { drainage }\end{array}$ & none & \begin{tabular}{|l|} 
gelatin \\
sponge, GDC \\
\end{tabular} & 6 \\
\hline $\begin{array}{l}\text { Tsukamoto } \\
\text { et al. } .^{30}\end{array}$ & 9 & 64 & $\mathrm{M}$ & unclear & $\begin{array}{l}\text { consciousness } \\
\text { disturbance }\end{array}$ & DRPLA & bilateral & $\begin{array}{l}\text { Burr hole, } \\
\text { drainage }\end{array}$ & steroids & PVA particles & 18 \\
\hline \multirow[t]{2}{*}{$\begin{array}{l}\text { Hashimoto } \\
\text { et al. }{ }^{31}\end{array}$} & 10 & 79 & $\mathrm{M}$ & yes & none & $\begin{array}{l}\text { peritoneal } \\
\text { mesothelioma }\end{array}$ & $\begin{array}{l}\text { right } \\
\text { side }\end{array}$ & $\begin{array}{l}\text { Burr hole, } \\
\text { irrigation }\end{array}$ & none & $16 \%$ NBCA & 3 \\
\hline & 11 & 55 & $\mathrm{M}$ & unavailable & unavailable & Heavy drinker & left side & $\begin{array}{l}\text { Burr hole, } \\
\text { irrigation }\end{array}$ & none & $20 \%$ NBCA & unavailable \\
\hline
\end{tabular}




\begin{tabular}{|l|l|l|l|l|l|l|l|l|l|l|l|}
\hline & 12 & 87 & M & unavailable & unavailable & none & left side & $\begin{array}{l}\text { Burr hole, } \\
\text { irrigation }\end{array}$ & none & $16 \%$ NBCA & unavailable \\
\hline 13 & 73 & F & unavailable unavailable & none & bilateral & $\begin{array}{l}\text { Burr hole, } \\
\text { irrigation }\end{array}$ & none & $\begin{array}{l}18 \% \text { NBCA } \\
200-\mu \mathrm{m} \text { PVA } \\
\text { particles }\end{array}$ & unavailable \\
\hline 14 & 68 & F & no & Disorientation & $\begin{array}{l}\text { warfarin } \\
\text { (Cerebral } \\
\text { infarction, } \\
\text { pulmonary } \\
\text { Embolism) }\end{array}$ & left side & $\begin{array}{l}\text { Burr hole, } \\
\text { irrigation }\end{array}$ & none & $20 \%$ NBCA & 4 \\
\hline
\end{tabular}

CSDH, chronic subdural hematoma; DRPLA, dentatorubral-pallidoluysian atrophy; GDC, Guglielmi detachable coils; MLS, midline shift; NBCA, N-butyl 2-cyanoacrylate; LOC, loss of consciousness; PVA, polyvinyl alcohol

TABLE 2

Factors associated with the recurrence of $\mathrm{CSDH}^{\star}$

\begin{tabular}{|c|c|c|c|}
\hline Patient factors & Laboratory findings & Imaging findings & Surgical factors \\
\hline -age & -liver dysfunction & -brain atrophy & -duration of \\
\hline$-\operatorname{sex}$ & -renal failure & -high and mixed-density & drainage \\
\hline -low GCS & -thrombocytepenia & $\mathrm{CSDH}$ & -residual air after \\
\hline -low GOS at discharge & -coagulation-factor & -bilateral CSDH & surgery \\
\hline -hemodialysis & deficiency & -midline shift more than 5 & \\
\hline -dementia & & $\mathrm{mm}$ & \\
\hline -diabetes & & -width of the hematoma & \\
\hline -epilepsy & & -cranial base hematoma & \\
\hline -APs or ACs & & -septum formation & \\
\hline \multicolumn{4}{|l|}{-chemotherapeutic agents } \\
\hline \multicolumn{4}{|c|}{-intracranial hypotension (CSF shunt } \\
\hline \multicolumn{4}{|l|}{ surgery) } \\
\hline \multicolumn{4}{|l|}{-hypertension } \\
\hline \multicolumn{4}{|l|}{-alcoholism } \\
\hline -postoperative patient posture & & & \\
\hline
\end{tabular}

${ }^{\star}$ These factors are still controversial

AC, anticoagulant; AP, antiplatelet; CSF,crebrospinal fluid; GCS, Glasgow coma scale, GOS, Glasgow outcome scale 
DOI: 10.2478/romneu-2014-0034

The first treatment that these patients received were: 1) burr hole plus drainage and irrigation, 2) burr hole plus drainage, or 3) burr hole plus irrigation. Several techniques were also used to treat hematoma recurrence, namely an additional surgery, irrigation, an Ommaya reservoir, and steroids. The materials used to embolize the MMA were: polyvinyl alcohol particles, 16-20\% N-butyl 2cyanoacrylate, gelatin sponges, and Guglielmi detachable coils.

No complications were reported after the MMA embolization procedure. Follow-up times ranged from 3 to 18 months, although follow-up times for patients 3 , and 11-13 were not available. Importantly, all 14 patients experienced no recurrences or enlargements of CSDH following embolization of the MMA.

\section{Discussion}

$\mathrm{CSDH}$ is one of the most common types of intracranial hemorrhage and it is associated with high levels of morbidity and mortality $(1.5-8 \%)(4,16,17)$. Patients with advanced age are more likely to have CSDH because of atrophy of the brain parenchyma. This atrophy enlarges subarachnoid spaces, thereby stretching veins that bridge these spaces (18). Stretched veins are more fragile and tend to rupture, releasing venous blood into the subdural space (19). Men are twice as likely as women to have $\mathrm{CSDH}$ because they experience more head injuries (20). Single or double burr holes with closed drainage systems (with or without irrigation) are currently the treatments of choice for this condition, but many others techniques have been described (21). The recurrence of $\mathrm{CSDH}$ following surgery is not uncommon, and can result from poor re-expansion of the brain, or inflammation and hemorrhage of the outer membrane (22).

Several factors are associated with $\mathrm{CSDH}$ recurrence, including advanced age, a tendency to bleed, brain atrophy, alcohol abuse, kidney and liver diseases, diabetes, epilepsy, anticoagulants, chemotherapy agents, intracranial hypotension, hemodialysis, the density of the hematoma, the width of the hematoma, insufficient intraoperative drainage, postoperative accumulation of air in the subdural space, bilateral CSDH, postoperative position, the Glasgow coma scale, and the Glasgow outcome scale $(7,11,16,17,23-26)$ (Table 2). Analyses concerning these associations, however, have yielded inconsistent results.

The treatment of recurrent CSDH remains controversial and many techniques have been used to manage this condition, including burr holes plus drainage, repeated irrigations, the installation of reservoirs and aspiration (12), subdural peritoneal shunts (13), capsule removal with large craniotomy, endoscopic perforation of the septum (14), and MMA embolization (15, 27-32).

Embolization of the MMA to treat CSDH was first reported by Mandai et al. (15) for patients with coagulopathy (cirrhosis of the liver). Application of this technique resulted in very positive patient outcomes. In one Japanese article Takahashi et al. (32) reported results concerning three patients with recurrent CSDH that had been subjected to several unsuccessful drainage procedures. After MMA embolization no hematoma 
enlargements were seen and all hematomas gradually and completely resolved (32). Tanaka et al. (33) performed superselective angiography of the MMA in a series of 35 patients. They found diffuse dilation of the MMA and scattered networks of abnormal vasculature, which seemed to be macrocapillaries within the outer membrane $(29,33)$. To understand the relationship between the MMA and the outer membrane in CSDH, Tanaka et al. (34) studied histological features of the outer membrane and observed many communicating arteries, i.e., arteries that originated from branches of the MMA and then entered the outer membrane. They concluded that the MMA provides nutrients to the abnormal membrane that surrounds the hematoma via these communicating arteries. As direct arterial pressure of the MMA may rupture these communicating arteries, MMA embolization may prevent or delay $\mathrm{CSDH}$ recurrence.

The most common materials used for the embolization procedure were: N-butyl 2cyanoacrylate, Guglielmi detachable coils, polyvinyl alcohol particles, and gelatin sponges. Using a low concentration of liquid $\mathrm{N}$-butyl 2-cyanoacrylate increases the therapeutic effect by embolizing more peripheral vessels associated with the MMA with a low risk of catheter adhesion $(28,31)$. To prevent the aberrant flow of blood into the ophthalmic artery, it is necessary to perform a pre-embolization study of the MMA pathway and its anastomosis with the internal carotid artery through the inferolateral trunk, or the feeding vessel to the facial nerve. If there is anastomosis between the MMA and the ophthalmic artery, embolization of the proximal MMA using coils or gelatin sponges should be considered (31).

Here we have review 14 cases in which MMA embolization was used to treat CSDH. None of these patients had post-operative complications, $\mathrm{CSDH}$ recurrence, or $\mathrm{CSDH}$ enlargement. It should be acknowledged, however, that this review does not contain Class I or Class II data, and that this analysis should be supplemented with more definitive data (e.g., randomized trials) when they become available. Results to date indicate that embolization of the MMA represents an effective option for treating recurrent $\mathrm{CSDH}$. It is is good option for patients who cannot tolerate invasive intervention such as repeated surgery (burr hole), capsule removal with large craniotomy or perforation of the septum with an endoscope. It can use as adjuvant therapy in treating recurrence of chronic subdural hematoma.

\section{Acknowledgments:}

We thank Dr. Samir Taha for his assistance throughout this study.

\section{Correspondence}

Gobran Taha Alfotih, MD

Department of Neurosurgery

Second Affiliated Hospital of Sun Yat-Sen

University

Guangzhou, GuangDong, 510120, China

E-mail:gta_alfotih@yahoo.com

Tel: +8613066381670

\section{References}

1. Baechli H, Nordmann A, Bucher HC,Gratzl O . Demographics and prevalent risk factors of chronic subdural haematoma: results of a large single-center cohort study. Neurosurg Rev. 2004;27:263-266. 
DOI: 10.2478/romneu-2014-0034

2. Forster MT, Mathé AK, Senft C, Scharrer I, Seifert V, Gerlach R. The influence of preoperative anticoagulation on outcome and quality of life after surgical treatment of chronic subdural hematoma. J Clin Neurosci. 2010;17:975-979.

3. Foelholm R, Waltimo O. Epidemiology of chronic subdural haematoma. Acta Neurochir (Wien). 1975;32:247-250.

4. Ramachandran $\mathrm{R}$, Hegde $\mathrm{T}$.Chronic subdural hematomas--causes of morbidity and mortality. Surg Neurol 2007; 67: 367-72.

5. König SA, Schick U, Döhnert J, Goldammer A, Vitzthum HE. Coagulopathy and outcome in patients with chronic subdural haematoma. Acta Neurol Scand 2003;107: 110-6.

6. Hong HJ, Kim YJ, Yi HJ, Ko Y, Oh SJ, Kim JM. Role of angiogenic growth factors and inflammatory cytokine on recurrence of chronic subdural hematoma. Surg Neurol 2009;71:161-5.

7. Abouzari M, Rashidi A, Rezaii J, Esfandiari K, Asadollahi M, Aleali $\mathrm{H}$, Abdollahzadeh $\mathrm{M}$. The role of postoperative patient posture in the recurrence of traumatic chronic subdural hematoma after burr-hole surgery. Neurosurgery. 2007;61:794-797.

8. Santarius T, Kirkpatrick PJ, Ganesan D, Chia HL, Jalloh I, Smielewski P, Richards HK, Marcus H, Parker RA, Price SJ, Kirollos RW, Pickard JD, Hutchinson PJ. Use of drains versus no drains after burr-hole evacuation of chronic subdural hematoma: a randomised controlled trial. Lancet. 2009; 374:1067-1073.

9. Wilberger JE. Pathophysiology of evolution and recurrence of chronic subdural hematoma. Neurosurg Clin N Am 2000;11:435-438.

10. Ko BS, Lee JK, Seo BR, Moon SJ, Kim JH, Kim SH.Clinical analysis of risk factors related to recurrent chronic subdural hematoma. J Korean Neurosurg Soc 2008;43:11-5.

11. Torihashi K, Sadamasa N, Yoshida K, Narumi O, Chin $\mathrm{M}$, Yamagata S. Independent predictors for recurrence of chronic subdural hematoma: a review of 343 consecutive surgical cases. Neurosurgery 2008;63:1125-9.

12. Sato M, Iwatsuki K, Akiyama C, Kumura E, Yoshimine T. Implantation of a reservoir for refractory chronic subdural hematoma. Neurosurgery 2001;48:1297-301.

13. Vinchon M, Noulé N, Soto-Ares G, Dhellemmes P. Subduroperitoneal drainage for subdural hematomas in infants: Results in 244 cases. J Neurosurg 2001;95:249-55.
14. Hellwig D, Kuhn TJ, Bauer BL, List-Hellwig E. Endoscopic treatment of septated chronic subdural hematoma. Surg Neurol 1996;45:272-7.

15. Mandai S, Sakurai M, Matsumoto Y. Middle meningeal artery embolization for refractory chronic subdural hematoma: Case report. J Neurosurg 2000;93:686-8.

16. Oishi M, Toyama M, Tamatani S, Kitazawa T, Saito M.Clinical factors of recurrent chronic subdural hematoma. Neurol Med Chir (Tokyo) 2001;41:382-386. 17. Yamamoto H, Hirashima Y, Hamada H, Hayashi N, Origasa $\mathrm{H}$, Endo S. Independent predictors of recurrence of chronic subdural hematoma : results of multivariate analysis performed using a logistic regression model. J Neurosurg 2003;98:1217-1221.

18. Roob G, Fazekas F. Magnetic resonance imaging of cerebral microbleeds. Curr Opin Neurol 2000;13:69-73.

19. Yamashima T, Friede RL. Why do bridging veins rupture into the virtual subdural space? J Neurol Neurosurg Psychiatry 1984;47:121-7

20. Sim YW, Min KS, Lee MS, Kim YG, Kim DH. Recent changes in risk factors of chronic subdural hematoma. J Korean Neurosurg Soc 2012; 52: 234-9.

21. Markwalder TM .Chronic subdural haematomas: a review.J Neurosurg 1981;54: 637-645.

22. Nagahori T, Nishijima M, Takaku A. Histological study of the outer membrane of chronic subdural hematoma: possible mechanism for expansion of hematoma cavity. No Shinkei Geka 1993;21:697-701.

23. El-Kadi H, Miele VJ, Kaufman HH. Prognosis of chronic subdural hematomas. Neurosurg Clin N Am 2000;11:553-567.

24. Amirjamshidi A, Abouzari M, Eftekhar B, Rashidi A, Rezaii J, Esfandiari K, Shirani A, Asadollahi M, Aleali H. Outcomes and recurrence rates in chronic subdural haematoma. Br J Neurosurg 2007;21:272-275.

25. Nakajima H, Yasui T, Nishikawa M, Kishi H, Kan M.The role of postoperative patient posture in the recurrence of chronic subdural hematoma: a prospective randomized trial. Surg Neurol $2002 ; 58: 385-387$.

26. Stanisic M, Lund-Johansen $M$, Mahesparan R. Treatment of chronic subdural hematoma by burr-hole craniostomy in adults:influence of some factors on postoperative recurrence. Acta Neurochir (Wien) 2005;147:1249-1256.

27. Hirai S, Ono J, Odaki M, Serizawa T, Nagano O. Embolization of the Middle Meningeal Artery for Refractory Chronic Subdural Haematoma. Usefulness for 
Patients under Anticoagulant Therapy. Interv Neuroradiol 2004;10Suppl 2:101-4.

28. Ishihara H, Ishihara S, Kohyama S, Yamane F, Ogawa M, Sato A, Matsutani M. Experience in endovascular treatment of recurrent chronic subdural hematoma. Interv Neuroradiol 2007;13Suppl 1:141-4.

29. Mino M, Nishimura S, Hori E, Kohama M, Yonezawa S, Midorikawa H, Kaimori M, Tanaka T, Nishijima M. Efficacy of middle meningeal artery embolization in the treatment of refractory chronic subdural hematoma. Surg Neurol Int 2010;1:78.

30. Tsukamoto Y, Oishi M, Shinbo J, Fujii Y.Transarterial embolisation for refractory bilateral chronic subdural hematomas in a case with dentatorubral-pallidoluysian atrophy. Acta Neurochir (Wien) 2011;153:1145-7.

31. Hashimoto T, Ohashi T, Watanabe D, Koyama S, Namatame H, Izawa H, Haraoka R, Okada H, Ichimasu $\mathrm{N}$, Akimoto J, Haraoka J. Usefulness of embolization of the middle meningeal artery for refractory chronic subdural hematomas. Surg Neurol Int 2013;4:104.

32. Takahashi K, Muraoka K, Sugiura T, Maeda Y, Mandai S, Gohda Y, Kawauchi M, Matsumoto Y. Middle meningeal artery embolization for refractory chronic subdural hematoma: 3 case reports. No Shinkei Geka 2002;30:535-9.

33. Tanaka T, Fujimoto S, Saitoh K, Satoh S, Nagamatsu $\mathrm{K}$, Midorikawa $\mathrm{H}$. Superselective angiographic findings of ipsilateral middle meningeal artery of chronic subdural hematoma in adults. No Shinkei Geka 1998; 26:339-47

34. Tanaka T, Fujimoto S, Saito K, Kaimori M.Histological study of operated cases of chronic subdural hematoma in adults: relationship between dura mater and outer membrane. No Shinkei Geka 1997;25:701-705 